\title{
USE OF CREEPING SPEED MODE IN DISCRETE CONTROL AND MEASURING EQUIPMENT WITH DIGITAL-PROGRAM CONTROL
}

\author{
Lubov Payuk ${ }^{*}$, Nataliya Voronina, Sergey Korepanov, Olga Galtseva, Nataliya Natalinova \\ Tomsk Polytechnic University, 634050, Tomsk, Russia
}

\begin{abstract}
The creeping speed mode is studied with calculation of the resultant vector of the flux linkage $\psi_{0}$ of the double-fed machine. It is shown that use of the double-fed machine as the actuating motor in the creeping speed mode increases the working off accuracy of the motion law. A mathematical model of the double-fed machine to study various modes of the CNC machine including the creeping speed mode is developed. The method to estimate the load parameters of the double-fed machine is presented. Practical implication of the study is confirmed by the results obtained in the evaluation of the influence of load parameters on the dynamic indicators of actuating electromotor.
\end{abstract}

\section{Introduction}

Currently, any measuring equipment incorporates the systems of the fixed current parameters, comparison with a reference element and compensation of the measuring error [1]. In these systems, modern CNC machines are used; many engines with relatively small power are involved in their work, the basic modes of operation of these engines are "unnatural" [2]. These modes include frequent reversal, braking by various ways (dynamic, double-current, capacitor-dynamic, etc.), getting the creeping speed according to the schemes for the joint feeding, step and torque modes, etc. [3-9].

The creeping speed mode is described in detail below. The feature of the creeping speed mode is an operation at the speed of the tool movement from 2 to $10 \mathrm{~mm} / \mathrm{min}$ [3]. This mode is widely used in the CNC machines (for processing and plasma cutting), aboard mechanisms of antenna rotation, detection systems for mobile and ground equipment, fixation systems of outdoor surveillance, textile industry (warp sizing machine), and discrete measurement systems with CNC (two-dimensional electromagnetic displacement sensors) [10-12]. In practice, this type of the tool movement is often implemented due to the presence of linear asynchronous engines (LAE), actuating motor and ball-and-screw unit or electromagnetic frame.

\footnotetext{
Corresponding author: lubapa81@mail.ru
} 


\section{Research method}

The method to develop the creeping speed in the double-fed machine (DFM) at the different inclusions of magnetic fields is presented. The analysis of influence of the load parameters on the dynamic indicators of actuating electromotor is carried out.

The double-fed machine is referred to as the controlled (full controlled) machine of alternating current; voltages are supplied to its stator and rotor clips. These voltages are composed of two components: voltage of compensation and voltage (law) of control. This type of electrical machines is known to be universal; it has high power characteristics. This electrical machine is implemented as a micromachine; it is a decisive factor for measurement systems $[13,14]$.

The creeping speed mode (Figure 1) is implemented in the feeding of stator and rotor windings of the DFM by sinusoidal voltage of different frequencies. In the first case, the difference between frequencies is $1 \mathrm{~Hz}$; in the second case, it is $40 \mathrm{~Hz}$ at the initial phase of the supply voltage $\varphi=\pi / 2$.

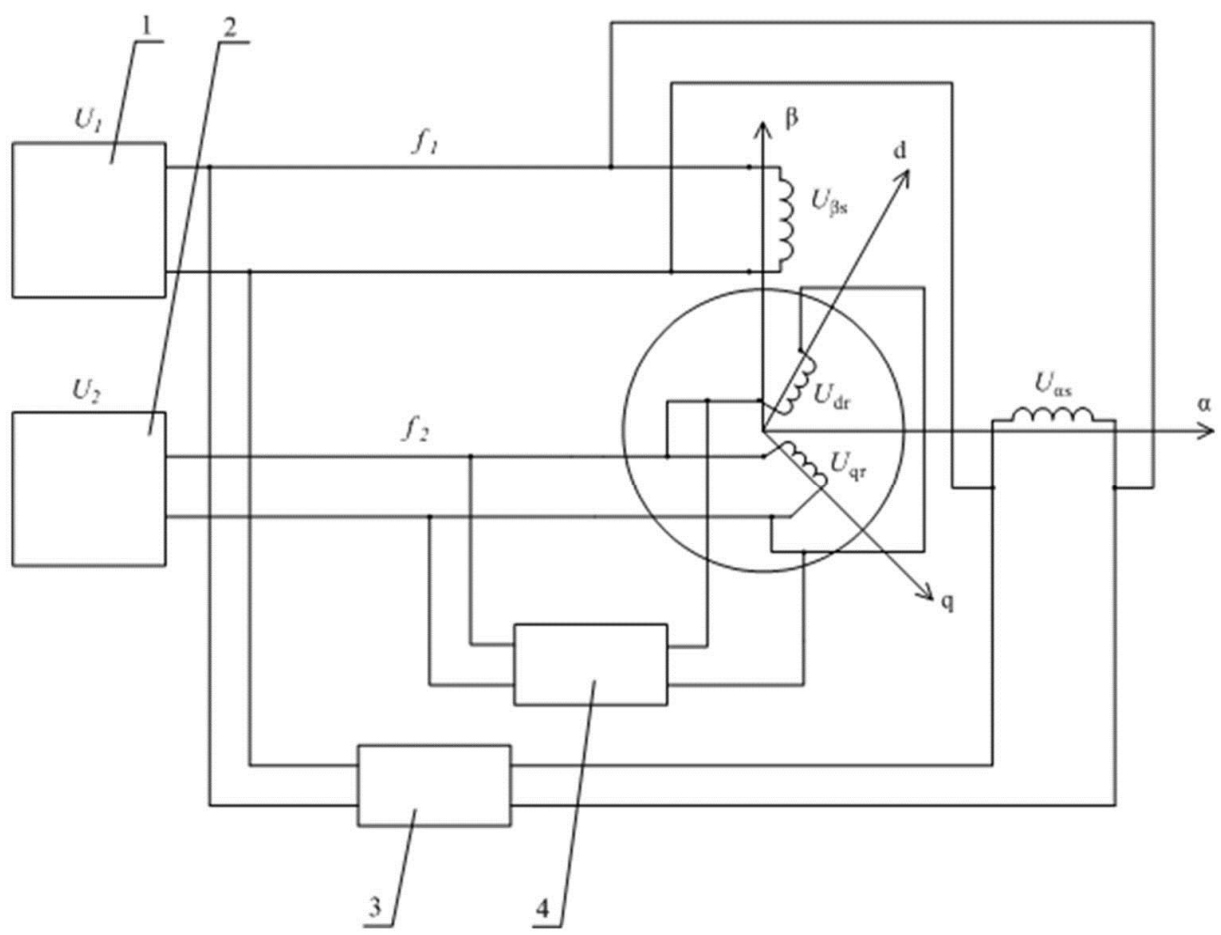

Figure 1. Feeding scheme of the double-fed machine in realization of the creeping speed mode: 1, 2 are the sources; 3,4 are the phase shifters.

The following equations are true for operation of the DFM in the creeping speed mode: $\omega_{1}=\omega_{2}=\omega$, and $\omega_{3}=\omega_{4}=\omega^{\prime}$ if $\alpha=\beta=\gamma=0, \varphi=\pi / 2$.

Equations (1) for the flux linkages of stator and rotor windings in the transformed coordinate system with due regard to the accepted assumptions and the mode of the machine operation are 


$$
\begin{gathered}
\psi_{\alpha s}=\psi_{m s} \sin (\omega t) ; \\
\psi_{\beta r}=\psi_{m s} \sin (\omega t) ; \\
\psi_{\alpha r}=\psi_{m r} \sin \left(\omega^{`} t\right) \cos \chi+\psi_{m r} \sin \left(\omega^{`} t+\frac{\pi}{2}\right) \sin \chi ; \\
\psi_{\beta r}=-\psi_{m r} \sin \left(\omega^{`} t\right) \sin \chi+\psi_{m r} \sin \left(\omega^{`} t+\frac{\pi}{2}\right) \cos \chi .
\end{gathered}
$$

Equations (2) for the squares of the real and imaginary parts of the generalized flux linkage vector are

$$
\begin{gathered}
\psi_{\alpha}^{2}=\left(\psi_{m s} \sin (\omega t)+\left(\psi_{m r} \sin \left(\omega^{`} t\right) \cos \chi+\psi_{m r} \cos \left(\omega^{`} t\right) \sin \chi\right)\right)^{2}= \\
=\left(\psi_{m s}\left(\sin (\omega t)+\mu\left(\sin \left(\omega^{`} t\right) \cos \chi+\cos \left(\omega^{\prime} t\right) \sin \chi\right)\right)\right)^{2}=\left(\psi_{m s}\left(\sin (\omega t)+\mu \sin \left(\omega^{`} t+\chi\right)\right)\right)^{2}, \\
\psi_{\beta}^{2}=\left(\psi_{m s} \sin (\omega t)-\left(\psi_{m r} \sin \left(\omega^{`} t\right) \sin \chi+\psi_{m r} \cos \left(\omega^{\prime} t\right) \cos \chi\right)\right)^{2}= \\
=\left(\psi_{m s}\left(\sin (\omega t)-\mu\left(\sin \left(\omega^{\prime} t\right) \sin \chi+\cos \left(\omega^{\prime} t\right) \cos \chi\right)\right)\right)^{2}=\left(\psi_{m s}\left(\sin (\omega t)-\mu \cos \left(\omega^{\prime} t-\chi\right)\right)\right)^{2} .
\end{gathered}
$$

Equations (3) for the amplitude value of the flux linkage vector in the creeping speed mode are

$$
\psi=\psi_{m s} \sqrt{\left(\sin (\omega t)+\mu \sin \left(\omega^{`} t+\chi\right)\right)^{2}+\left(\sin (\omega t)-\mu \cos \left(\omega^{`} t-\chi\right)\right)^{2}} .
$$

Equations (2) for the movement of the spatial vector of flux linkage in the air gap for the creeping speed mode (3) are

$$
\begin{gathered}
\chi_{0}=\operatorname{arctg}\left(\frac{\psi_{m s} \sin (\omega t)-\psi_{m r} \sin \left(\omega^{\prime} t\right) \sin \chi+\psi_{m r} \cos \left(\omega^{`} t\right) \cos \chi}{\psi_{m s} \sin (\omega t)+\psi_{m r} \sin \left(\omega^{\prime} t\right) \cos \chi+\psi_{m r} \cos \left(\omega^{\prime} t\right) \sin \chi}\right)= \\
=\operatorname{arctg}\left(\frac{\sin (\omega t)-\mu\left(\sin \left(\omega^{\prime} t\right) \sin \chi+\cos \left(\omega^{`} t\right) \cos \chi\right)}{\sin (\omega t)+\mu\left(\sin \left(\omega^{\prime} t\right) \cos \chi+\cos \left(\omega^{\prime} t\right) \sin \chi\right)}\right)= \\
=\operatorname{arctg}\left(\frac{\sin (\omega t)-\mu \sin \left(\omega^{`} t+\chi\right)}{\sin (\omega t)+\mu \cos \left(\omega^{\prime} t-\chi\right)}\right) .
\end{gathered}
$$

Figure 2 shows hodographs of the resultant flux linkage vector at the feeding of stator and rotor windings from the current and voltage sources. Two rotating electromagnetic fields arise during the DFM operation in the creeping speed mode for hodograph of the resultant vector of flux linkage $\psi_{0}$ : the first field is generated by the frequency $f_{1}=f_{2}=50 \mathrm{~Hz}$ and the second one is generated by $f_{3}=f_{4}=51 \mathrm{~Hz}$ from the primary and secondary elements respectively. 


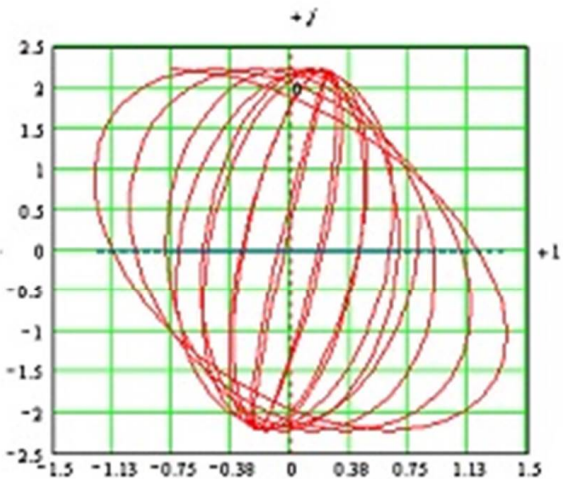

(a)

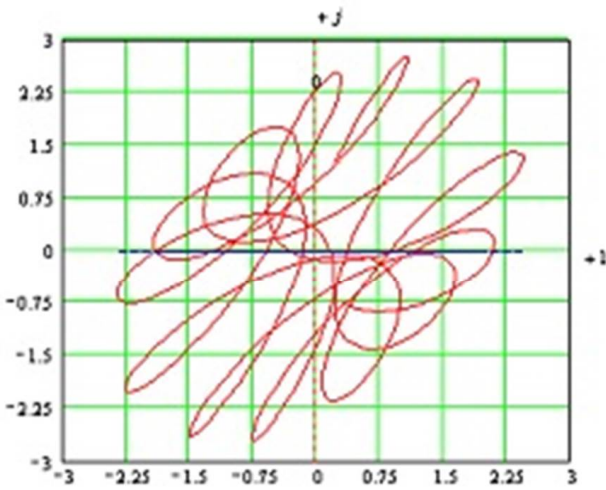

(b)

Figure 2. Hodographs of vectors $\psi_{0}$ at the feeding of stator and rotor windings from the current sourse (a) and from the voltage sourse (b) at $\omega_{1}=\omega_{2}=1 ; \omega_{3}=\omega_{4}=1.02$.

Consider two variants of interaction of the magnetic fields in the DFM in the creeping speed mode:

1. It is necessary to set the following signals of the control system at the consonant interaction of electromagnetic fields: $\gamma_{1}=\gamma_{2}=1 ; \quad \gamma_{3}=\gamma_{4}=1.225 ; \quad \omega_{1}=\omega_{2}=\omega ; \quad \omega_{3}=\omega_{4}=\omega$; $\alpha=\beta=\gamma=0, \varphi=\pi / 2$. The voltages on the clips of stator and rotor windings in transformed axes $\alpha, \beta, 0$ are in the following form:

$$
\begin{gathered}
U_{\alpha \mathrm{s}}=U_{\mathrm{ms}} \sin (\omega \mathrm{t}) ; \\
U_{\beta \mathrm{s}}=U_{\mathrm{ms}} \sin (\omega \mathrm{t}) ; \\
U_{\alpha \mathrm{r}}=U_{\mathrm{mr}} \sin \left(\omega^{`} \mathrm{t}\right) \cos \chi+U_{\mathrm{mr}} \sin \left(\omega^{`} \mathrm{t}+\phi\right) \sin \chi ; \\
U_{\beta \mathrm{r}}=-U_{\mathrm{mr}} \sin \left(\omega^{`} \mathrm{t}\right) \sin \chi+U_{\mathrm{mr}} \sin \left(\omega^{`} \mathrm{t}+\phi\right) \cos \chi .
\end{gathered}
$$

2 . In the case of the opposite interaction of electromagnetic fields the angular frequency of rotation and the initial phases on the axes are set similarly to the above case $\gamma_{1}=\gamma_{2}=1$; $\gamma_{3}=1.225 ; \gamma_{4}=-1.225$. Equations for the voltages on the clips of the stator and rotor windings are similar to the system (5) with the only difference: the sign "+" before the second summand is replaced for the sign " $-"$ in the second part of the two equations.

A mathematical model of DFM is given relative to the currents of stator and rotor in the axes $\alpha, \beta, 0$ in the iterative form at zero initial conditions. It is presented in the system (6). DFM was based on the asynchronous engine with phase rotor 4AK160S8UZ with protection degree of IP44, and its asynchronous rotational speed is $n=750 \mathrm{rpm}$ with power $\mathrm{P}_{2}=5.5[\mathrm{~kW}]$.

This model allows investigating transients in the DFM in various modes of its operation. Table 1 shows the parameters of actuating motor 4AK160S8UZ.

Table 1. Parameters of actuating motor 4AK160S8UZ.

\begin{tabular}{|c|c|c|c|c|c|c|c|c|c|c|}
\hline \multicolumn{2}{|c|}{ Energy indicators } & \multicolumn{4}{|c|}{ Mechanical characteristic } & \multicolumn{5}{|c|}{ Equivalent circuit parameters } \\
\hline $\cos \varphi$ & $\mathrm{p}$ & $\eta$ & $\mathrm{m}_{\mathrm{m}}$ & $\mathrm{S}_{\mathrm{nom}}$ & $\mathrm{S}_{\text {crit }}$ & $\mathrm{X}_{\mu}$ & $\mathrm{R}_{1}^{\prime}$ & $\mathrm{X}_{1}^{\prime}$ & $\mathrm{R}_{2}^{\prime}$ & $\mathrm{X}_{2}^{\prime}$ \\
\hline$[\mathrm{pu}]$ & {$[-]$} & {$[\%]$} & {$[\mathrm{pu}]$} & {$[\%]$} & {$[\%]$} & {$[\mathrm{pu}]$} & {$[\mathrm{pu}]$} & {$[\mathrm{pu}]$} & {$[\mathrm{pu}]$} & {$[\mathrm{pu}]$} \\
\hline 0.7 & 4 & 80 & 0.5 & 6.4 & 9 & 1.6 & 0.06 & 0.11 & 0.094 & 0.175 \\
\hline
\end{tabular}


Gabriel Kron's equations are the basis for the DFM mathematical model. Gabriel Kron's equations are the system of differential equations of voltages and motions with due regard to the accepted assumptions and describe the energy transformations in the electric machine. It is also necessary to calculate the base values and coefficients of the model, which are shown in Tables 2 and 3.

Table 2. Estimated base values of parameters of actuating motor.

\begin{tabular}{|c|c|c|c|c|c|c|c|c|c|c|}
\hline \multicolumn{4}{|c|}{ Main base values } & \multicolumn{7}{|c|}{ Auxiliary base values } \\
\hline $\mathrm{U}_{\mathrm{b}}$ & $\mathrm{I}_{\mathrm{b}}$ & $\mathrm{P}_{\mathrm{b}}$ & $\omega_{\mathrm{b}}$ & $t_{b}$ & $Z_{b}$ & $\mathrm{~L}_{\mathrm{b}}$ & $\mathrm{M}_{\text {mech. } \mathrm{b}}$ & $\mathrm{L}_{\text {mech. } b}$ & $\mathrm{R}_{\mathrm{mec}}$ & $\mathrm{C}_{\text {mech. } \mathrm{b}}$ \\
\hline$\Sigma$ & $\mathbb{\Xi}$ & 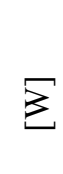 & 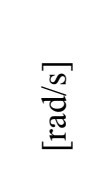 & $\tilde{\omega}$ & $\Xi$ & $\Xi$ & $\begin{array}{l}\vec{\pi} \\
\dot{\pi} \\
\dot{3} \\
\dot{z}\end{array}$ & 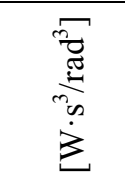 & 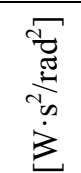 & $\begin{array}{l}\overrightarrow{\tilde{T}} \\
\frac{\pi}{\infty} \\
\dot{z}\end{array}$ \\
\hline 311.1 & 18.2 & 8.5 & 314.3 & 0.0032 & 17.07 & 0.054 & 108.297 & 0.00439 & 1.38 & 433.19 \\
\hline
\end{tabular}

Table 3. Coefficients of mathematical model [pu].

\begin{tabular}{|c|c|c|c|c|c|c|}
\hline$\sigma$ & $\alpha_{\mathrm{S}}$ & $\alpha_{\mathrm{S}}^{\prime}$ & $\alpha_{\mathrm{r}}$ & $\alpha_{\mathrm{r}}^{\prime}$ & $\mathrm{k}_{\mathrm{S}}$ & $\mathrm{k}_{\mathrm{r}}$ \\
\hline 0.158 & 3.702 & 0.222 & 3.756 & 0.213 & 0.935 & 0.901 \\
\hline
\end{tabular}

Mathematical model of DFM is of the form [pu]:

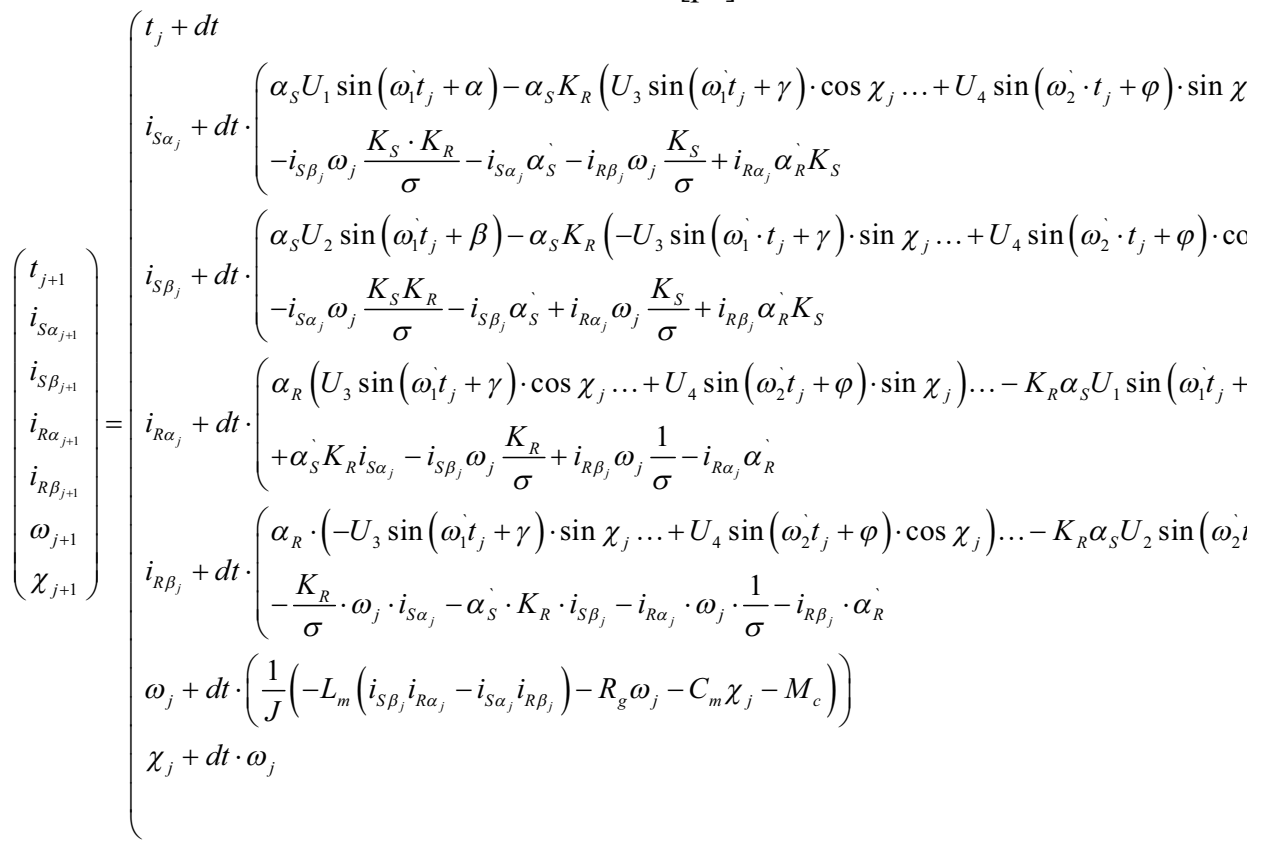

where $R_{g}$ is a coefficient of damping torque of load; $C_{m}$ is a coefficient of position torque of load; $J$ is a total torque of inertia of engine; $M_{c}$ is a torque of static load on the shaft of engine; $\chi$ is a law of motion of the movable element. 


\section{Results and discussion}

Figure 3 shows results of mathematical modelling of the DFM (6). As an example, the dependencies of the DFM electromagnetic torque in the starting and creeping speed modes are presented.

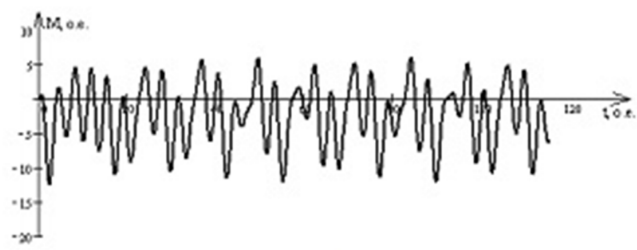

(a)

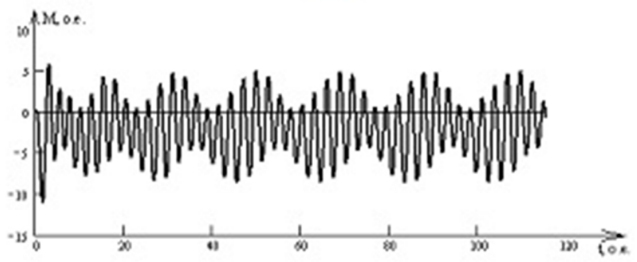

(b)

Figure 3. Dependence of electromagnetic moment on the time at the frequency difference of $1 \mathrm{~Hz}$ (a) and of $40 \mathrm{~Hz}(\mathrm{~b})$.

The dependencies were obtained by the modelling; they are adequate and the model is sustainable. The disadvantage is inability to investigate the model in case of simultaneous changes in the load parameters.

The influence of load parameters on the dynamic indicators of actuating motor is important as the additional disturbances and measurement errors lead to incorrect measurement results. The load torque of inertia $J_{n}$ (from 80 to $2500 \mathrm{pu}$ ) is selected as a changeable load parameter.

Figure 4 shows the results of investigation of dynamic indicators: time of transition process $\tau_{t p}$ and shock values of electromagnetic torque $M_{s h}$ on load torque of inertia $J_{n}$.

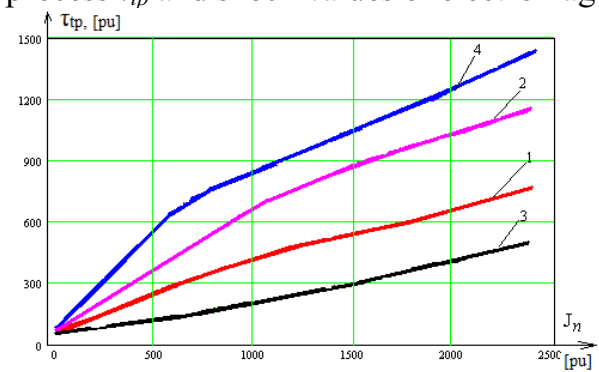

(a)

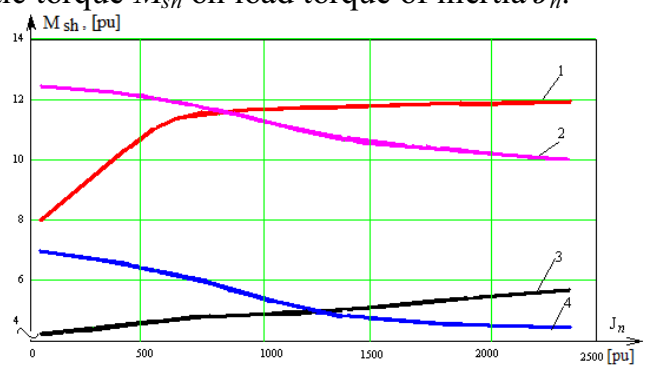

(b)

Figure 4. Dependence of time of transition process (a) and shock values of electromagnetic torque (b) on inertia load: consonant interaction of electromagnetic fields at the frequency difference of $1 \mathrm{~Hz}$ (curve 1) and of $40 \mathrm{~Hz}$ (curve 3); opposite interaction of electromagnetic fields of $1 \mathrm{~Hz}$ (curve 2) and of $40 \mathrm{~Hz}$ (curve 4).

In the creeping speed mode, the change in time of the transition process on load torque of inertia $\tau_{t p}=f\left(J_{n}\right)$ is observed to increase; it is typical of special modes of electromechanical energy converters based on the DFM. 
In the case of the consonant interaction of electromagnetic fields, the shock values of electromagnetic torque $M_{s h}$ decrease with the increase in the inertia torque of load $J_{n}$ (Figure 4, b, curves 1 and 3 ), and these values increase in the case of the opposite interaction of electromagnetic fields (Figure 4, $b$, curves 2 and 4).

\section{Conclusion}

1. The change of the load torque of inertia $J_{n}$ leads to the increase in time of transition process $\tau_{t p}$ and decrease in the shock values of electromagnetic torque $M_{s h}$ in the case of the consonant interaction of electromagnetic fields. With the same load parameters, the DFM has the maximal time of transition process at the consonant interaction of electromagnetic fields and at the frequency difference of $40 \mathrm{~Hz}$.

2. The practical application of the DFM in discrete-measuring systems of the CNC machines is possible with some limitations: the frequency difference must not exceed $10 \mathrm{~Hz}$.

\section{References}

[1] N.M. Natalinova, O.V. Galtseva, E.A. Moldovanova, 2016 Third International Conference on Electrical, Electronics, Computer Engineering and their Applications (EECEA), 52 (2016) doi: 10.1109/EECEA.2016.7470765

[2] M.H. Fisher, Magnetic amplifier creeping speed control Patent US 2663833A, (1953)

[3] A.V. Aristov, N.A. Voronina, Device for control two-phase asynchronous motor in the intermittent movement mode Patent RF 2009125766/22 (2009)

[4] L.A. Payuk, N.A. Voronina, O.V. Galtseva, J. Phys.: Conf. Ser. 671, 012044 (2016) doi: 10.1088/1742-6596/671/1/012044

[5] N.S. Starikova, V.V. Redko, G.V. Vavilova, J. Phys.: Conf. Ser. 671, 012056 (2016) doi: 10.1088/1742-6596/671/1/012056

[6] Y.A. Chursin, E.M. Fedorov, Optics\&Laser Technol. 67, 86 (2015) doi: 10.1016/j.optlastec.2014.09.017

[7] A.P. Surzhikov, T.S. Frangulyan, S.A. Ghyngazov, Lysenko, E.N., J. Therm. Anal. Calorim. 102 , 883 (2010) doi: 10.1007/s10973-010-0912-8

[8] L. Kozlova, E. Bolovin, L. Payuk, IOP Conf. Ser.: Mater. Sci. Eng. 132, 012005 (2016) doi: 10.1088/1757-899X/132/1/012005

[9] M.V. Kuimova, D.D. Burleigh, Yu.Yu. Arnst, A.E. Sentsov, Ponte 72, 127 (2016)

[10] R. Kodermyatov, M. Ivanov, M. Yuzhakov, V. Kuznetsov, M. Yuzhakova, E. Timofeeva, MATEC Web of Conferences 48, 05004 (2016) doi: 10.1051/confmatec/20164805004

[11] V.Y. Kazakov, D.K. Avdeeva, M.G. Grigoriev, N.M. Natalinova, I.V. Maksimov, M.V. Balahonova, BLM 7, 1 (2015)

[12] O.V. Galtseva, S.V. Bordunov, N.M. Natalinova, S.V. Mazikov, IOP Conf. Ser.: Mater. Sci. Eng. 132, 012003 (2016) doi: 10.1088/1757-899X/132/1/012003

[13] L. Cheng, X.J. Ye, D. R. Sun, Y.Y. Ye, Y. Jin, Appl. Mech. Mat. 416-417, 652 (2013) doi: 10.4028/www.scientific.net/AMM.416-417.652

[14] A.Y. Petrova, O.N. Chaikovskaya, I.V. Plotnikova, Tech. Phys. J. 60, 592 (2015) doi: $10.1134 / \mathrm{S} 1063784215040222$ 